\title{
PERANCANGAN DASHBOARD INTERAKTIF PENJUALAN (STUDI KASUS : PT JAYA BAKERY )
}

\author{
Sulistiawati $^{1)}$, Heni Sulistiani ${ }^{2)}$ \\ ${ }^{1)}$ Sistem Informasi, Universitas Teknokrat Indonesia \\ ${ }^{2)}$ Informatika, Universitas Teknokrat Indonesia \\ Jl. H.ZA Pagaralam, No 9-11, Labuhanratu,Bandarlampung \\ Email : sulistia0123@gmail.com ${ }^{1)}$,henisulistiani@teknokrat.ac.id ${ }^{2)}$
}

\begin{abstract}
Abstrak
Monitoring penjualan pada PT Jaya Bakery masih dilakukan dengan melihat laporan penjualan dalalm bentuk tabel yang disajikan dalam aplikasi spreadsheet oleh bagian penjualan. Hal tersebut tentu saja membutuhkan waktu yang lama dalam mendapatkan informasi tentang perkembangan penjualan karena laporan tersebut tidak update perharinya. Pimpinan kesulitan dalam proses pengambilan keputusan yang berkaitan dengan penjualan, karena data yang disajikan tidak real time dan terkadang terdapat kesalahan data dalam penyajiannya.

Salah satu alternatif pemecahan masalah yang bisa diterapkan adalah dengan membangun sistem dashboard interaktif penjualan. Sistem dashboard interaktif ini dapat mempermudah bagian penjualan dalam menyajikan laporan penjualan secara real time dan memudahkan pimpinan dalam melihat perkembangan penjualan dan melakukan pengolahan data penjualan. Sehingga transaksi penjualan yang terjadi pada saat itu dapat terkontrol dengan baik oleh pimpinan.
\end{abstract}

Kata kunci: Dashboard, penjualan, transaksi

\section{Pendahuluan}

Sejalan dengan cepatnya perkembangan bidang teknologi, penggunaan internet yang menjurus kepada cyberspace sepertinya akan merubah seluruh kegiatan di masa kini dan masa datang. Secara umum akan berubah menjadi alat untuk persaingan antara perusahaan yang satu dengan yang lainnya. Penjualan adalah kegiatankegiatan bisnis dengan tujuan mengambil keuntungan seperti penjualan, pembelian, pelayanan, informasi, dan perdagangan melalui perantara yaitu melalui suatu jaringan komputer, memudahkan costumer untuk dapat melakukan transaksi jual beli tanpa harus datang ke tempatnya (Ipnuwati, 2011).

Dashboard merupakan sebuah model aplikasi sistem informasi yang disediakan bagi para manajer untuk menyajikan informasi kualitas kinerja, dari sebuah perusahaan atau lembaga organisasi (Ilhamsyah, 2017). Tampilan dashboard sangat sederhana karena bagian strategik tidak bertanggung jawab terhadap interaksi secara langsung terhadap data. Penelitian serupa pernah dilakukan oleh Anggoro, et al (2015), yang merancang sebuah Dashboard Information System sebagai
Pendukung Keputusan dalam Penjualan Tiket Pesawat, sistem yang dibangun mampu membantu pihak manajemen dalam memonitoring performance perusahaan untuk melakukan pengambilan keputusan dalam upaya meningkatkan penjualan tiket pada perusahaan. Khatulistiwa (2016), merancang sebuah dashboard yang mampu menampilkan visualisasi penjualan pulsa. Tampilan dashboard tersebut disajikan dalam bentuk penyedia voucher dengan penjualan kategori, voucher penjualan yang berkontribusi dalam permintaan, penjualan oleh pelanggan, cluster berbasis penjualan, target pencapaian penjualan dan target deposit. Khodiyah (2012), juga membangun sebuah media yang dapat digunakan untuk sarana bertransaksi bagi distributor dan agen kecil maupun konsumen pada umumnya sehingga mempermudah berbelanja dan bertransaksi. Jauhari (2010) juga mengembangkan sebuah E-commerce untuk membantu mengembangkan UKM yang ada di Indonesia.

PT Jaya Bakery merupakan perusahaan yang bergerak dibidang penjualan, dan dalam proses monitoring penjualan diperlukan sebuah sistem yang mampu menyajikan perkembangan penjualan roti yang disajikan dalam bentuk visualisasi berupa laporan dalam bentuk grafik disertai tabel yang berguna bagi manajemen dalam menunjang suatu keputusan. Karena pada saat ini PT Jaya Bakery masih melakukan monitoring penjualan dengan cara melihat laporan penjualan yang disajikan dalam aplikasi spreadsheet. Hal tersebut tentu saja membutuhkan waktu yang lama dalam mendapatkan informasi tentang perkembangan penjualan karena laporan tersebut tidak bersifat real time. Pimpinan mengalami kesulitan dalam proses pengambilan keputusan yang berkaitan dengan penjualan, karena data yang disajikan tidak real time dan terkadang terdapat kesalahan data dalam penyajiannya.

Penelitian ini membahas tentang perancangan dashboard interaktif penjualan yang mampu menampilkan visualisasi monitoring penjualan roti dalam bentuk grafik selama satu priode tertentu, sistem ini diharapkan dapat membantu kegiatan pelaporan penjualan pada PT Jaya Bakery dan memudahkan pimpinan dalam melihat perkembangan penjualan dan melakukan pengolahan data penjualan serta proses pengambilan keputusan. 


\section{Pembahasan}

Tahap awal dalam penelitian ini adalah merumuskan masalah yang akan dijadikan sebagai objek penelitian. Perumusan masalah dilakukan dengan terlebih dahulu melihat kondisi aktual dilapangan. Masalah yang ada pada PT Jaya Bakery adalah tidak adanya sistem untuk memonitoring perkembangan penjualan dan melakukan pengolahan data penjualan. Metode pengumpulan data yang dilakukan adalah melalui wawancara, pengamatan, dokumentasi terhadap pihak-pihak yang berwenang dalam penjualan di Jaya Bakry.

Analisis kebutuhan sistem dilakukan untuk mengetahui kebutuhan pengguna terhadap sistem yang akan dikembangkan. Hal ini perlu dilakukan agar sistem yang dikembangkan sesuai dengan kebutuhan pengguna. Terdapat dua kebutuhan sistem yaitu analisis kebutuhan fungsional dan non fungsional.

\section{a. Analisis kebutuhan Fungsional}

1) Sistem yang dikembangkan dapat mengolah data penjualan

2) Sistem yang dikembangkan dapat mengahasilkan output berupa laporan stok kue dan laporan penjualan

3) Sistem yang dikembangkan dapat melakukan monitoring dan menampilkan grafik dari data penjualan per periode

\section{b. Analisis Kebutuhan Non Fungsional}

Adapun alat penelitian yang digunakan dalam penelitian ini terdiri dari perangkat keras (hardware) dan perangkat lunak (software), uraian perangkat yang digunakan dapat dilihat pada tabel 1 .

Tabel 1. Kebutuhan Non Fungsional

\begin{tabular}{|l|l|}
\hline $\begin{array}{c}\text { Perangkat Keras } \\
\text { (Hardware) }\end{array}$ & \multicolumn{1}{|c|}{$\begin{array}{c}\text { Perangkat Lunak } \\
\text { (Software) }\end{array}$} \\
\hline 1. Processor : Intel Core & 1. Sistem operasi \\
2 Duo 3,2 Ghz & Microsoft Windows 7 \\
2. Harddisk 320 GB & 2. SQLyog enterprise \\
3. Monitor 14" & $\begin{array}{l}\text { 3. Dreamweaver } \\
\text { 4. Mouse dan Keyboard }\end{array}$ \\
& $\begin{array}{l}\text { 4. Appserv win-32.2.5.8 } \\
\text { 5. Browser : Google } \\
\text { crome, dan Mozila } \\
\end{array}$ \\
& Firefox \\
\hline
\end{tabular}

Setelah dilakukan analisis kebutuhan dari sistem yang akan dibagun, tahapan selanjutnya yaitu melakukan analisis sistem yang sedang berjalan pada pengolahan dan pemantauan penjualan di PT Jaya Bakery, tujuannya untuk mengetahui lebih jelas bagaimana cara kerja sistem tersebut dan masalah yang dihadapi agar dapat dikembangkan sistem yang baru secara terkomputerisasi, perancangan analisis sistem yang sedang berjalan yang dilakukan berdasarkan urutan kejadian yang ada. Setelah melakukan analisis sistem berjalan, selanjutnya melakukan evaluasi terhadap sistem yang sedang berjalan. Hasil evaluasi terhadap sistem yang sedang berjalan dapat dilihat pada tabel 2 .
Tabel 2. Evaluasi Sistem Berjalan

\begin{tabular}{|c|c|c|}
\hline No & Permasalahan & Penyelesaian \\
\hline 1. & $\begin{array}{lr}\text { Pengolahan } & \text { data } \\
\text { penjualan } & \text { masih } \\
\text { dilakukan } & \text { secara } \\
\text { manual yaitu } & \text { dengan } \\
\text { mencatat } & \text { data } \\
\text { penjualan } & \text { kedalam } \\
\text { buku } & \text { penjualan } \\
\text { sehingga } & \text { dalam } \\
\text { pembuatan laporan } \\
\text { harus membutuhkam } \\
\text { waktu cukup lama } \\
\text { karena data penjualan } \\
\text { harus di entri terlebih } \\
\text { dahulu r kedalam } \\
\text { aplikasi spreadsheet. }\end{array}$ & $\begin{array}{l}\text { Mengembangkan sebuah } \\
\text { sistem pengolahan data } \\
\text { penjualan dimana data } \\
\text { penjualan } \\
\text { langsung di entri ke } \\
\text { aplikasi, sehingga tidak } \\
\text { harus melakukan } \\
\text { pencatatan kedalam buku } \\
\text { penjualan sehingga dalam } \\
\text { pembuatan laporan akan } \\
\text { lebih cepat dan tepat } \\
\text { waktu. }\end{array}$ \\
\hline 2. & $\begin{array}{lr}\text { Pemantauan } \\
\text { penjualan } \\
\text { dilakukan masih } \\
\text { melihat dengan } \\
\text { penjualan } r \text { laporan } \\
\text { tabel hal itu membuat } \\
\text { pimpinan ataupun } \\
\text { bagian penjualan } \\
\text { lambat dalam } \\
\text { mengetahui informasi } \\
\text { perkembangan secara } \\
\text { cepat. }\end{array}$ & $\begin{array}{l}\text { Mengembangkan sistem } \\
\text { untuk memonitoring } \\
\text { perkembangan penjualan } \\
\text { secara real-time dalam } \\
\text { visualisasi grafik } \\
\text { penjualan sehingga } \\
\text { pimpinan ataupun bagian } \\
\text { penjualan dapat langsung } \\
\text { diketahui oleh pimpinan. }\end{array}$ \\
\hline
\end{tabular}

Rancangan dari sistem dibangun dapat dilihat pada gambar 1. Aktor dari sistem ini terdiri dari dua, yaitu pimpinan dan admin yang mempunyai fungsi berbeda. Pimpinan dapat mengelola laporan penjualan, melihat tampilan data stok dan tampilan data penjualan dalam bentuk grafik. Sedangkan admin dapat melakukan kegiatan pengelolaan data kue dan penjualan.

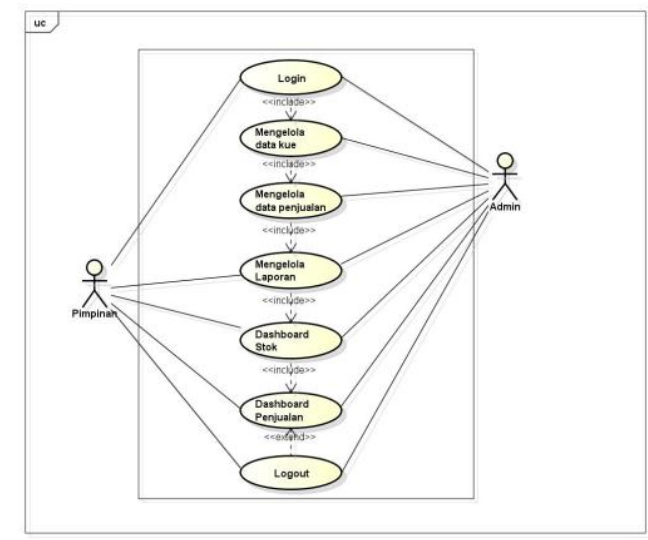

Gambar 1. Use Case Diagram Sistem Dashboard

Tampilan form transaksi yang merupakan entri data penjualan dan menjadi acuan dasar untuk menampilkan visualisasi dashboard dapat dilihat pada gambar 2 . Tampilan dari dashboard penjualan perhari yang dibangun dapat dilihat pada gambar 3, tampilan dashboard data kue per-tahun dapat dilihat pada gambar 4. 


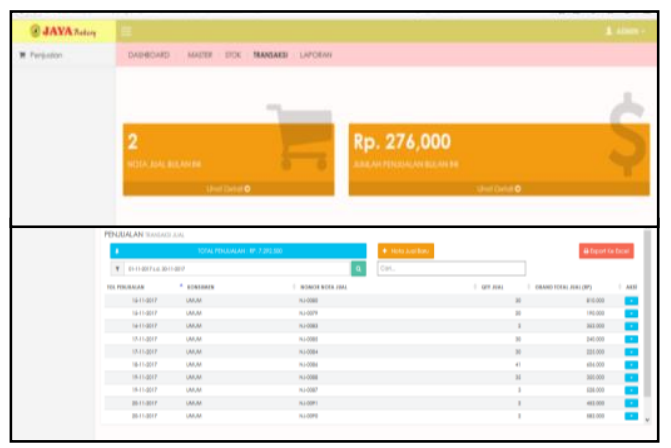

Gambar 2. Tampilan Form Transaksi

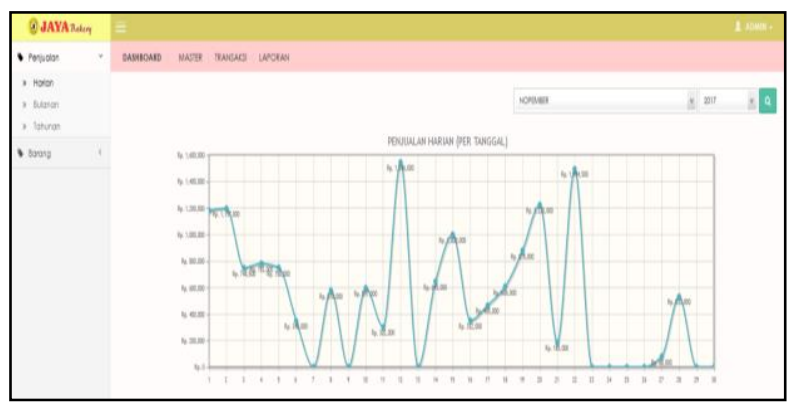

Gambar 3. Tampilan Dashboard Penjualan per-hari

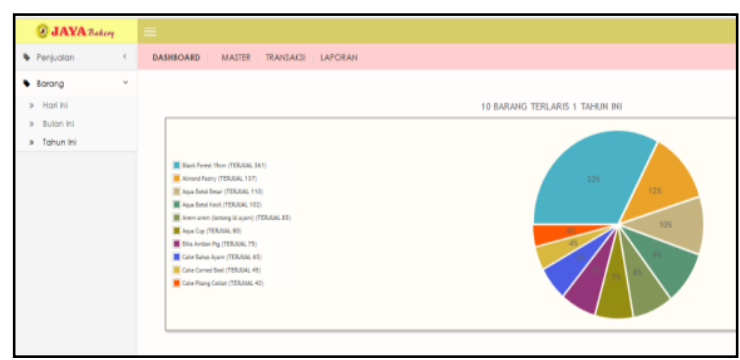

Gambar 4. Tampilan Dashboard Penjualan per-hari

Sedangkan untuk tampilan penjualan per-bulan dapat dilihat pada gambar 5 dan dibuat berbeda dengan tampilan sebelumnya.

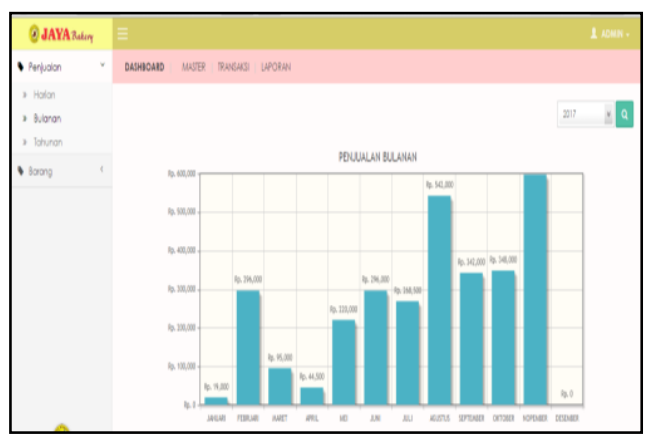

Gambar 5. Tampilan Dashboard Penjualan Per-Bulan

Sistem yang dibangun selain menghasilkan output dalam bentuk visualisasi grafik, juga menghasilkan nota transaksi penjualan sebagai bukti bagi konsumen. Tampilan nota transaksi penjualan dapat dilihat pada gambar 6.

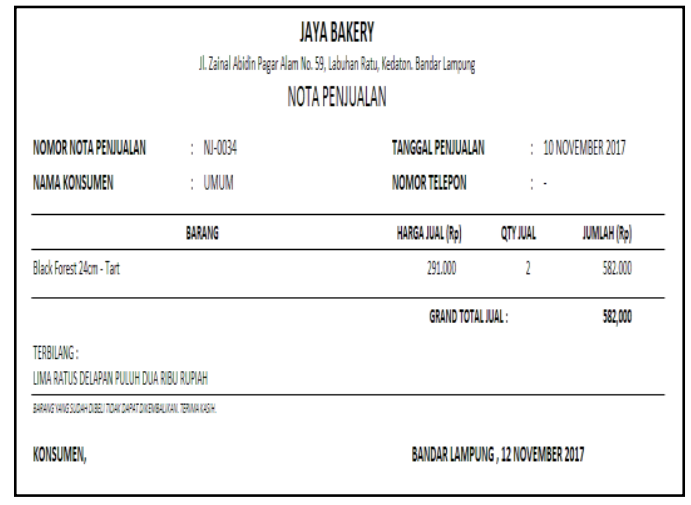

Gambar 6. Tampilan Nota Transaksi Penjualan

\section{Kesimpulan}

Perancangan dashboard inetraktif pada Jaya Bakery dimulai dari metode pengumpulan data (wawancara, pengamatan, dokumentasi) menggunakan metode pengembangan waterfall sehingga dibuatlah rancangan sistem menggunakan $U M L$, desain sistem inputan menggunakan PHP (Dreamwaver) dan MySQL yang akan mempermudah admin dalam mendapatkan informasi penjualan melalui dasboard. Hasil dari perancangan sistem yang dibangun, mampu memvisualisasikan data penjualan dalam bentuk grafik dan menghasilkan output berupa nota transaksi penjualan. Dengan tampilan tersebut, dapat mempermudah pimpinan untuk melakukan monitoring terhadap penjualan roti pada Jaya Bakry.

\section{Daftar Pustaka}

Anggoro, D. 2015. Dashboard Information System Sebagai Pendukung Keputusan Dalam Penjualan Tiket Pesawat Studi Kasus: PT. Nurindo Tour. Jurnal Sistem Informasi.

Ipnuwati, S. 2011. Perancangan Sistem Informasi Penjualan Pada Toko Minak Singa. Jurnal Sistem Informasi Dan Telematika .

Ilhamsyah. 2017. Sistem Informasi Penjualan Benang Tekstil Acrylic Berbasis Web (Studi Kasus PT. Acryl Textile Mills Tangerang). Jurnal Sistem Informasi.

Jauhari, J. 2010. Upaya Pengembangan Usaha Kecil Dan Menengah (UKM) Dengan Memanfaatkan ECommerce. Jurnal Sistem Informasi .

Khatulistiwa, A. 2016. Dashboard Untuk Visualisasi Penjualan Voucher Pulsa Elektrik Di Rajawali Reload Mojokerto. Jsika.

Khodiyah, S. 2012. Perancangan Sistem Informasi Penjualan Berbasis Website Pada Distro Busana Muslim Sekido. Jurnal Sistem Informasi. 